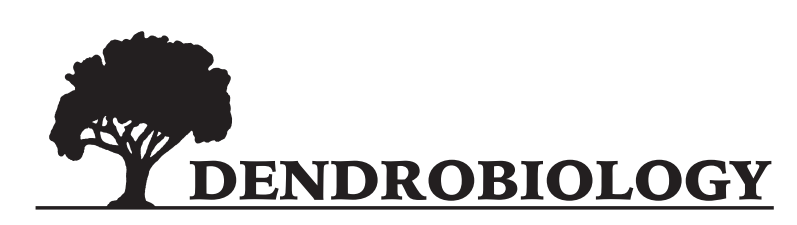

2019, vol. 82, 43-51

http://dx.doi.org/10.12657/denbio.082.005

\author{
Andrej Kormuták, Martin Galgóci, Peter Boleček, Dušan Gömöry
}

\title{
Effect of storage on pollen viability in Pinus sylvestris L., Pinus mugo Turra and their hybrid swarms
}

Received: 18 September 2019; Accepted: 21 January 2020

\begin{abstract}
Pollen storage is the only way how to overcome the differences in phenology of forest trees and geographically determined reproductive barriers between them during controlled pollination. Pollen viability of Scots pine (Pinus sylvestris L.), mountain dwarf pine (P. mugo Turra) and their hybrid swarms was evaluated after 3 -years storage at $-20^{\circ} \mathrm{C}$ using in vitro germination test. One population of each $P$. sylvestris and $P$. mugo were involved into study along with three hybrid swarms. Germination potential of the stored pollen grains was reduced significantly in comparison with freshly collected pollen. Profound decrease in germination rate was recorded in the two hybrid swarms (4.0-4.7\%), less profound in the remaining three populations $(0.6-2.4 \%)$. Pollen tube length, as the second pollen viability trait was reduced in stored pollen grains in a larger extend ranging between $51.4 \%$ and $54.3 \%$. The pollen grains of the species $P$. mugo was exception in this respect yielding pollen grains whose growth was retarded of $21.9 \%$ only. Analysis of variance confirmed significant differences between fresh and stored pollen grains. Statistically significant were also the differences between compared populations and between tested individuals of the respective populations.
\end{abstract}

Keywords: pines, hybrids, stored pollen, quality

Adresses: A. Kormuták, M. Galgóci, Plant Science and Biodiversity Center, Slovak Academy of Sciences, Institute of Plant Genetics and Biotechnology, Akademická 2, P. O. Box 39A, SK-950 07 Nitra, Slovak Republic, e-mail: nrgrkorm@savba.sk, martin.galgoci@savba.sk

P. Boleček, Constantine Philosophy University, Faculty of Natural Sciences, A. Hlinku 1, 94974 Nitra, Slovak Republic, e-mail: pbolecek@ukf.sk

D. Gömöry, Technical University in Zvolen, Faculty of Forestry, T. G. Masaryka 24, SK-960 53 Zvolen,

Slovak Republic, e-mail: dusan.gomory@vsld.tuzvo.sk

\section{Introduction}

Short or long-term storage belongs among the most important activity associated with pollen handling. It enables to overcome the differences in pollen shedding and ovule receptivity during controlled pollination of the trees on the same locality or the trees in widely separated regions (Binder et al., 1974). The methods used for pollen extraction along with storage temperature, moisture content of the pollen and relative humidity during storage play a decisive role in retaining viability of stored pollen (Ehrenberg, 1960). Optimal values of these factors and their combination may differ in individual groups of plants depending on structure and chemistry of their pollen. Angiosperms have for example been shown to possess a higher content of water in their pollen than gymnosperms (Stanley \& Linskens, 1974). Accordingly, the storage temperature for their pollen oscillates around $0^{\circ} \mathrm{C}$ or little below as compared 
with much more lower temperature regime required by the pollen of gymnosperms. The experience obtained in this field in the past resulted in the conclusion that freeze temperature $-20^{\circ} \mathrm{C}$ and $5-7 \%$ moisture content of the pollen may be a general and practical way of pine pollen storage from one season to the next (Nepamuceno Martínez \& Garza López, 1994). A variety of opinions exist regarding relative humidity within storage container, but commonly suggested is the relative humidity ranging between $10 \%$ and 22\% (Stanley et al., 1962; Snyder, 1961). The attempt by Copes (1985) to store the Douglas-fir pollen in liquid nitrogen $\left(-196^{\circ} \mathrm{C}\right)$ for the period of 1 year resulted in a negligible decrease of pollen viability only as evidenced by seed quality from controlled pollination of the species in which both the fresh and stored pollen were used. Also, the liquid nitrogen pretreatment is a part of the commonly used procedure of the long-term storage in pollen bank in Québec (Canada). The collected and dried pollen is first soaked in liquid nitrogen for three min then freeze-dried at $-65^{\circ} \mathrm{C}$ for $15 \mathrm{~min}$ and finally stored in a vacuum at $-30^{\circ} \mathrm{C}$ (Mercier, 1995). Based on in vitro germination data, the pure species populations of $P$. sylvestris and $P$. mugo were repeatedly found to exhibit a higher viability of their pollen than hybrid swarms $P$. sylvestris $\times P$. mugo whose pollen was characteristic by reduced germination percentage and shorter pollen tubes (Kormuták et al., 2007, 2019). Nothing is known about the response of these taxa towards the long-term storage of their pollen. In present study, we have tested this aspect of pollen biology in Scots pine, mountain dwarf pine and their hybrid swarms using freeze storage and in vitro germination test.

\section{Methods}

\section{Material}

The study involved the hybrid swarm populations of Scots pine (Pinus sylvestris L.) and mountain dwarf pine (P. mugo Turra) in Suchá Hora, Zuberec and Obšivanka in the western part of the High Tatra Mtns., Slovakia, along with the neighbour P. sylvestris population in Hruštín and P. mugo population in Vrátna valley. The locations of the populations and number of trees subjected to analysis are given in Table 1 .
Mountain dwarf pine population in Vrátna valley was represented by a homogeneous stand of mature trees with similar age. Scots pine population in Hruštín involves prevailingly old trees growing as soliters, to a lesser degree also the young trees of the adjoining stand. Hybrid swarm populations growing on peat-bog in Zuberec and on calcareous rocks on Obšívanka are rather heterogeneous consisting of trees which are of different age and of variable habitus. Hybrid swarm in Suchá Hora is exceptional in this respect exhibiting low variation in phenotype and height. Pollen collection in these populations was made in 2015. Owing to climatic conditioning of the pollen maturation process and different altitude occurrence of the respective populations, the pollen harvest extended on individual localities over 17 days starting on May 23, 2015 in Hruštín, Zuberec and Suchá Hora on lower altitudes and finishing on June 8, 2015 on Obšívanka and Vrátna valley on higher altitudes. Mature microstrobili of individual trees of a given population were harvested 2-3 days before massive pollen release, when the first indications of pollen shedding in some strobili were registered after shaking of twigs. The harvested microstrobili were placed in paper bags with sufficient aeration and transferred to the laboratory in the same day. The microstrobili were layed out on a sheet and left on a sunny side of the laboratory for two days. Ripe pollen was extracted from desiccated microstrobili by sieving. The sieved pollen was left additional 2-3 hours in the lab to dry more completely. The dry pollen was stored in the glass test tubes which were plugged loosely with cottonwool caps and placed into desiccator with potassium hydroxide. Storage temperature was $-20^{\circ} \mathrm{C}$, relative humidite (R. H.) inside desiccator was $27-30 \%$. Pollen was stored for the period of three years.

\section{In vitro germination test}

The germination test was preceeded by the experimental sucrose concentration optimization in cultivation medium using freshly collected pollen grains of one hybrid swarm individual from Zuberec and five sucrose concentration variants $(3 \%, 7 \%, 10 \%$, $13 \%, 16 \%)$. The pollen germination of compared populations has subsequently been done at $25^{\circ} \mathrm{C}$, separately for each tree, on the medium consisting of $1.5 \%$ agar and $10 \%$ sucrose (Brewbaker \& Kwack,

Table 1. Geographic characteristics of populations and number of trees used in the experiment

\begin{tabular}{|c|c|c|c|c|c|}
\hline Species/Population & Locality & Altitude & Longitude & Latitude & Number of trees \\
\hline P. sylvestris & Hruštín & $700 \mathrm{~m}$ & $19^{\circ} 21^{\prime} 39^{\prime \prime}$ & $49^{\circ} 19^{\prime} 18^{\prime \prime}$ & 21 \\
\hline P. mugo & Vrátna valley & $1230 \mathrm{~m}$ & $19^{\circ} 01^{\prime} 52^{\prime \prime}$ & $49^{\circ} 11^{\prime} 16^{\prime \prime}$ & 10 \\
\hline Hybrid swarm & Suchá Hora & $765 \mathrm{~m}$ & $19^{\circ} 47^{\prime} 11^{\prime \prime}$ & $49^{\circ} 23^{\prime} 20^{\prime \prime}$ & 14 \\
\hline Hybrid swarm & Zuberec & $815 \mathrm{~m}$ & $19^{\circ} 36^{\prime} 25^{\prime \prime}$ & $49^{\circ} 16^{\prime} 25^{\prime \prime}$ & 20 \\
\hline Hybrid swarm & Obšívanka & $1171 \mathrm{~m}$ & $19^{\circ} 01^{\prime} 59^{\prime \prime}$ & $49^{\circ} 15^{\prime} 20^{\prime \prime}$ & 7 \\
\hline
\end{tabular}


1963). Each sample was triplicated. The pollen was evenly dusted on the gel surface in small Petri dishes of $47 \mathrm{~mm}$ diameter by blowing it from a soft-hair brush. Each dish was placed in a larger Petri dish (70 $\mathrm{mm}$ ) containing $2 \mathrm{ml}$ of $\mathrm{H}_{2} \mathrm{O}$ and covered with a cap. The incubation of pollen was restricted by 2 days during which the integrity of growing pollen tubes was preserved (Fig. 1). Three days' incubation has as a rule led to bursting of a considerable amount of pollen tubes. Also, the prolong incubation is often accompanied by the infection of cultivation medium by fungi and bacteria spores from pollen surface and from the air (Razmologov, 1964). After $48 \mathrm{~h}$ incubation in the dark, the number of germinating pollen was recorded from a random sample of 100 pollen grains, whereas the pollen tube length was measured in a sample of 30 pollen grains of each Petri dish. The pollen grain was taken for viable when its pollen tube reached the length comparable with the diameter of pollen grain body (Razmologov, 1964). In total, the germination percentage evaluation is based on the 43200 counts involving three replications per tree and 72 tested individuals with fresh and stored pollen, each evaluated separately. Likewise, the pollen tube length data totalled 12960 measurements of the same kind as given above. The evaluation was made with NU 2 microscope (Carl Zeiss Jena) using $7 \times$ eyepiece with a scale and $10 \times$ objective. The photography of germinating pollen grains were taken with Axioplan 2 microscope and AxioVision 48 softwer. The differences in germination percentage and pollen tube length were tested with regard to the different years, populations and trees using the two-way ANOVA. Germination percentages were arcsine-transformed prior to analysis. The following model was used:

$$
v_{\mathrm{ijkl}}=\mu+\alpha_{\mathrm{i}}+\beta_{\mathrm{j}}+\alpha \beta_{\mathrm{ij}}+\gamma(\beta)_{\mathrm{jk}}+\varepsilon_{\mathrm{ijkl}}
$$

where $\mu$ is the general mean, $\alpha_{i}$ is the fixed effect of the $\mathrm{i}^{\text {th }}$ year, $\beta_{\mathrm{j}}$ is the fixed effect of the $\mathrm{j}^{\text {th }}$ population, $\alpha \beta_{\mathrm{ij}}$ is the year $\times$ population interaction, $\gamma(\beta)_{\mathrm{jk}}$ is the nested effect of the $k^{\text {th }}$ tree within the $j^{\text {th }}$ population, and $\varepsilon_{\mathrm{ijkl}}$ is the random error. Calculations were done using the GLM procedure of the statistical package SAS (https://support.sas.com/documentation/94/. Pairwise differences between population means were tested by Duncan's test.

\section{Results}

The experimental evaluation of the effect of sucrose content in cultivation medium on pollen germination proved the $10 \%$ concentration to be optimal for both pollen viability parameters examined (Fig. 1).

The pollen grain germination percentage ranged within the narrow limits rather reaching $95 \%$ on medium without sucrose and $98.3 \%$ on medium with $10 \%$ sucrose. The remaining sucrose concentration variants exerted an intermediate effect in this respect. Duncan's test has positioned all these variants into one common group (Table 2). ANOVA has not confirmed statistical significancy of the differences between tested variants, either $(\mathrm{P}=0.4472)$.

Contrary to pollen grain germination, the response of pollen tube growth to the presence of sucrose in medium was much more sensitive. Similar tendency as with pollen germination was also observed in the pollen tube length variation, the shortest pollen tubes being registered on medium without sucrose as well as on the medium with the highest sucrose concentration. The corresponding values for pollen tube length reached $107.6 \mu \mathrm{m}$ and $92.9 \mu \mathrm{m}$, respectively. The longest pollen tubes were obtained on medium with $10 \%$ sucrose averaging at $165.2 \mu \mathrm{m}$.
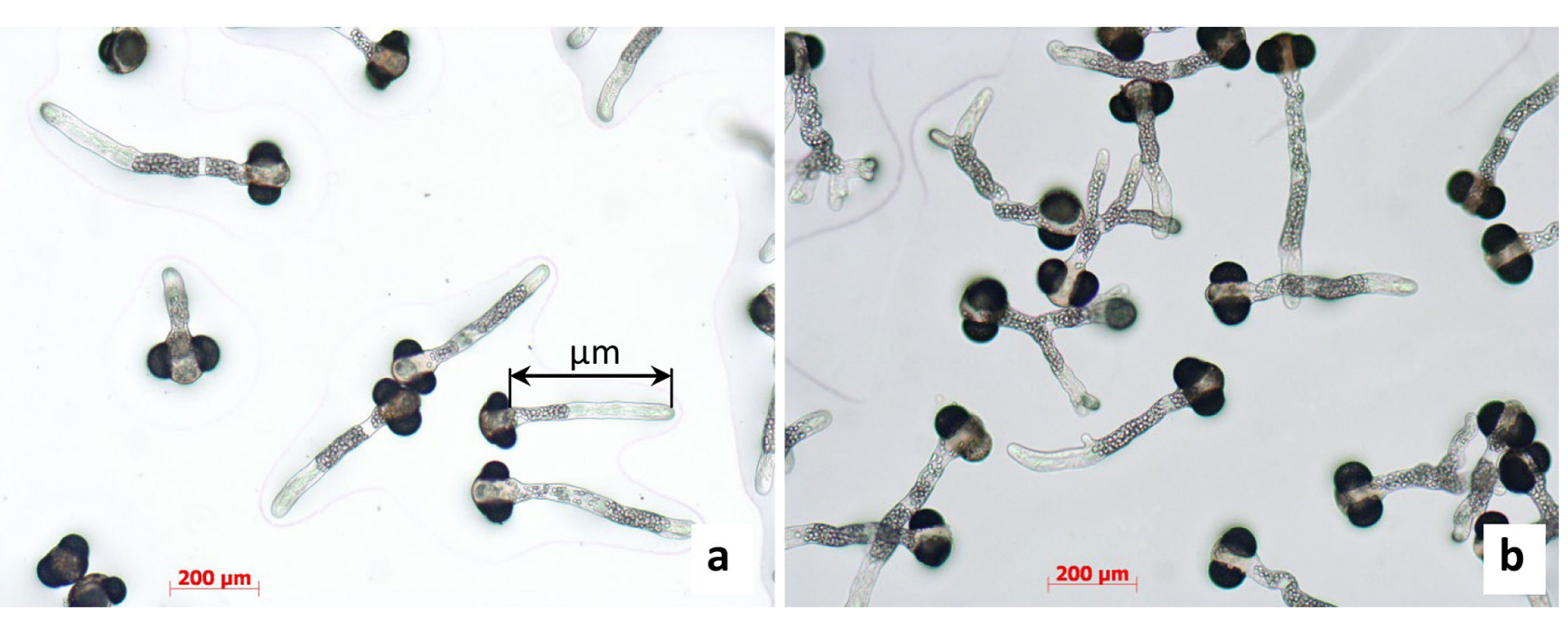

Fig. 1 Germinating pollen grains of P. sylvestris with linear pollen tubes (a) and P. mugo with linear and ramnified pollen tubes (b); Bidirectional arrow indicates the beginning and tip of the pollen tube as considered in measurements 
Statistical significancy of the differences in pollen tube length on media with different sucrose concentration confirmed both Duncan's test and ANOVA (Tables 3-4).

Cytological illustration of different responses of the pollen grains to the varying content of sucrose in medium is given in Fig. 2.

A uniform response of the pollen towards storage conditions was registered in all the five populations

investigated with a more or less conspicuous decline of germination percentage and pollen tube length during storage. The only exception were in this respect the pollen grains of $P$. mugo with increased germination after 3-years storage as compared to fresh pollen. In general, the germination potential of the fresh pollen grains was relatively high ranging between $88.2 \%$ and $95.4 \%$. The corresponding characteristics of the pollen tube length varied within

Table 2. Effect of sucrose concentration on pollen germination in a hybrid swarm individual

\begin{tabular}{|c|c|c|c|c|c|}
\hline Sucrose conc. [\%] & $\mathrm{N}$ & $\begin{array}{c}\text { Germination }[\%] \\
\text { mean } \pm \text { s.d. }\end{array}$ & Min. & Max. & Duncan grouping \\
\hline 0 & 300 & $95.00 \pm 1.00$ & 94.00 & 96.00 & $\mathrm{~A}$ \\
\hline 3 & 300 & $96.33 \pm 1.52$ & 95.00 & 98.00 & A \\
\hline 7 & 300 & $97.33 \pm 2.30$ & 96.00 & 100.00 & A \\
\hline 10 & 300 & $98.33 \pm 2.08$ & 96.00 & 100.00 & A \\
\hline 13 & 300 & $97.66 \pm 3.21$ & 94.00 & 100.00 & A \\
\hline 16 & 300 & $96.00 \pm 2.00$ & 94.00 & 98.00 & A \\
\hline
\end{tabular}

$\mathrm{N}$ - number of evaluated pollen grains.

The letter A indicates statistically the absence of differences between tested sucrose concentrations variants.

Table 3 Effect of sucrose concentration in cultivation medium on pollen tube growth of a hybrid swarm individal

\begin{tabular}{|c|c|c|c|c|c|c|}
\hline Sucrose conc. [\%] & Repetitions & $\mathrm{N}$ & $\begin{array}{c}\text { Mean } \pm \text { s.d. } \\
{[\mu \mathrm{m}]}\end{array}$ & $\begin{array}{l}\text { Min. } \\
{[\mu \mathrm{m}]}\end{array}$ & $\begin{array}{l}\text { Max. } \\
{[\mu \mathrm{m}]}\end{array}$ & Duncan grouping \\
\hline \multirow[t]{4}{*}{0} & 1 & 30 & $113.33 \pm 44.27$ & 68.00 & 221.00 & \\
\hline & 2 & 30 & $113.90 \pm 44.67$ & 51.00 & 221.00 & \\
\hline & 3 & 30 & $95.76 \pm 41.75$ & 51.00 & 204.00 & \\
\hline & mean & 30 & 107.66 & & & $\mathrm{D}$ \\
\hline \multirow[t]{4}{*}{3} & 1 & 30 & $141.66 \pm 52.12$ & 51.00 & 238.00 & \\
\hline & 2 & 30 & $125.23 \pm 39.04$ & 51.00 & 238.00 & \\
\hline & 3 & 30 & $100.86 \pm 42.33$ & 51.00 & 221.00 & \\
\hline & mean & 30 & 122.58 & & & $\mathrm{C}$ \\
\hline \multirow[t]{4}{*}{7} & 1 & 30 & $137.13 \pm 71.56$ & 51.00 & 306.00 & \\
\hline & 2 & 30 & $143.93 \pm 43.45$ & 68.00 & 238.00 & \\
\hline & 3 & 30 & $130.33 \pm 54.37$ & 51.00 & 255.00 & \\
\hline & mean & 30 & 137.13 & & & B \\
\hline \multirow[t]{4}{*}{10} & 1 & 30 & $159.80 \pm 46.09$ & 68.00 & 255.00 & \\
\hline & 2 & 30 & $166.03 \pm 68.97$ & 51.00 & 289.00 & \\
\hline & 3 & 30 & $170.00 \pm 47.24$ & 85.00 & 272.00 & \\
\hline & mean & 30 & 165.27 & & & A \\
\hline \multirow[t]{4}{*}{13} & 1 & 30 & $121.26 \pm 39.10$ & 68.00 & 204.00 & \\
\hline & 2 & 30 & $154.13 \pm 48.27$ & 85.00 & 272.00 & \\
\hline & 3 & 30 & $141.10 \pm 59.42$ & 51.00 & 255.00 & \\
\hline & mean & 30 & 138.83 & & & B \\
\hline \multirow[t]{4}{*}{16} & 1 & 30 & $69.70 \pm 38.25$ & 17.00 & 136.00 & \\
\hline & 2 & 30 & $103.13 \pm 38.38$ & 51.00 & 187.00 & \\
\hline & 3 & 30 & $105.18 \pm 49.12$ & 10.00 & 204.00 & \\
\hline & mean & 30 & 92.94 & & & E \\
\hline
\end{tabular}

$\mathrm{N}$ - number of measured polllen tubes.

Different letters of Duncan's test indicate significant differences in pollen tube length registered on tested media.

Table 4. Analysis of variance of pollen tube growth on media with different sucrose concentrations

\begin{tabular}{lrrrrc}
\hline \multicolumn{1}{c}{ Source } & DF & Sum of squares & Mean square & F & P \\
\hline Sucr. conc. & 5 & 297374,5266 & 59474,9059 & 9,32 & 0,0008 \\
Repetitions & 12 & 76576,7977 & 6381,3998 & 2,64 & 0,0020 \\
Error & 524 & 1267864,6750 & 2419,5890 & & \\
\hline
\end{tabular}


a span of $118.3-143.4 \mu \mathrm{m}$. Both the parental species and their hybrid swarms exhibited some variation in viability parameters within freshly collected and stored pollen grain lots. In fresh pollen grains, the comparable germination percentages were characteristic for the P. mugo species and all the three hybrid swarm populations with germinability above $92 \%$. The P.sylvestris population was exception deviating
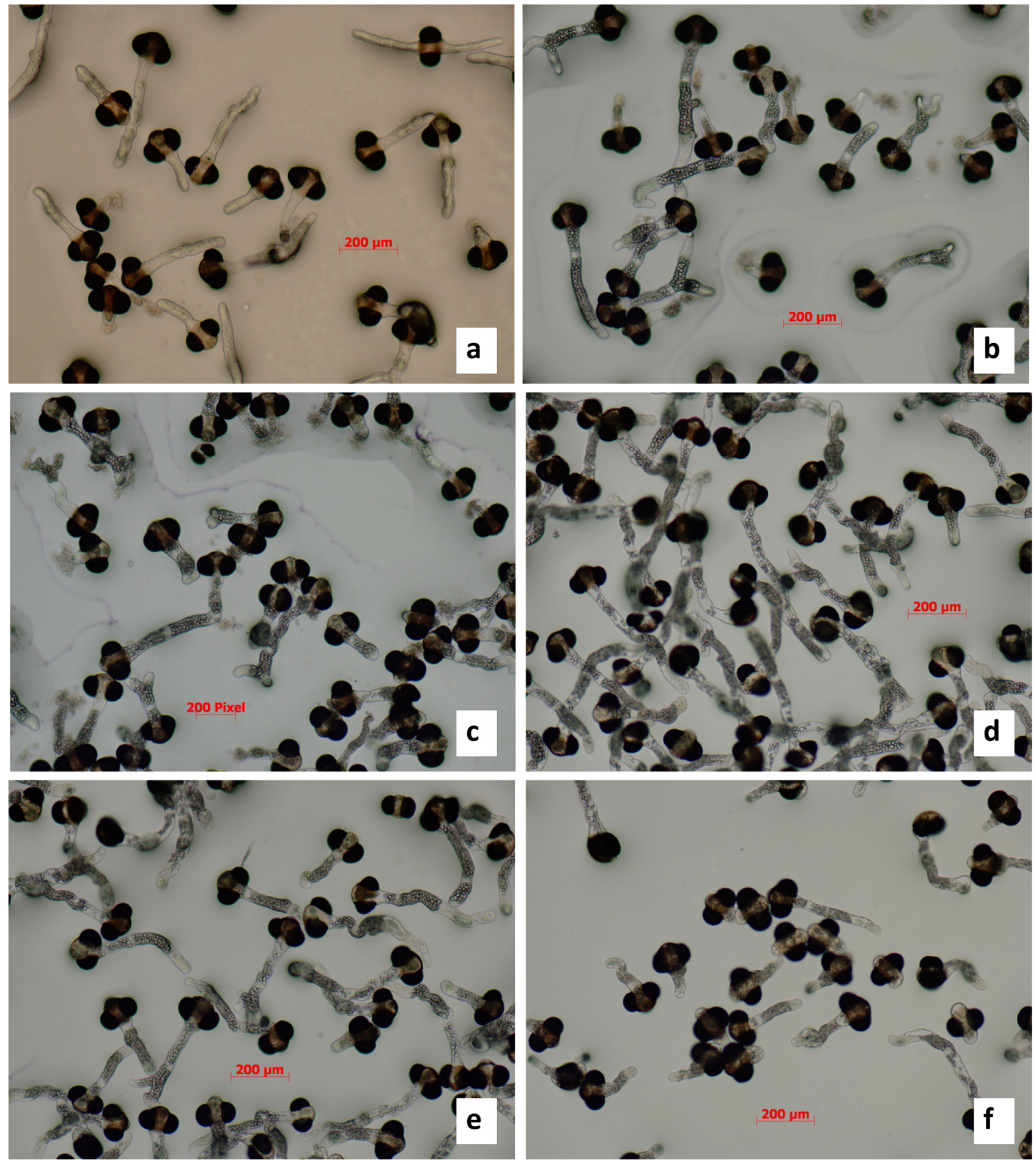

Fig. 2 Pollen grain germination on medium without sucrose (a) and on media with $3 \%$ (b), 7\% (c), 10\% (d), 13\% (e) and $16 \%$ (f) sucrose concentrations

conspicuously by its low germinability $(88.2 \%)$ from the rest of populations investigated (Table 5).

It was not possible to delineate at the freshly collected pollen level between germination potential of the parental species $P$. sylvestris and $P$. mugo on the one hand and their hybrid swarms on the other hand. Only the pollen tube length reflected to some degree the pure species status of $P$. sylvestris and P. mugo with
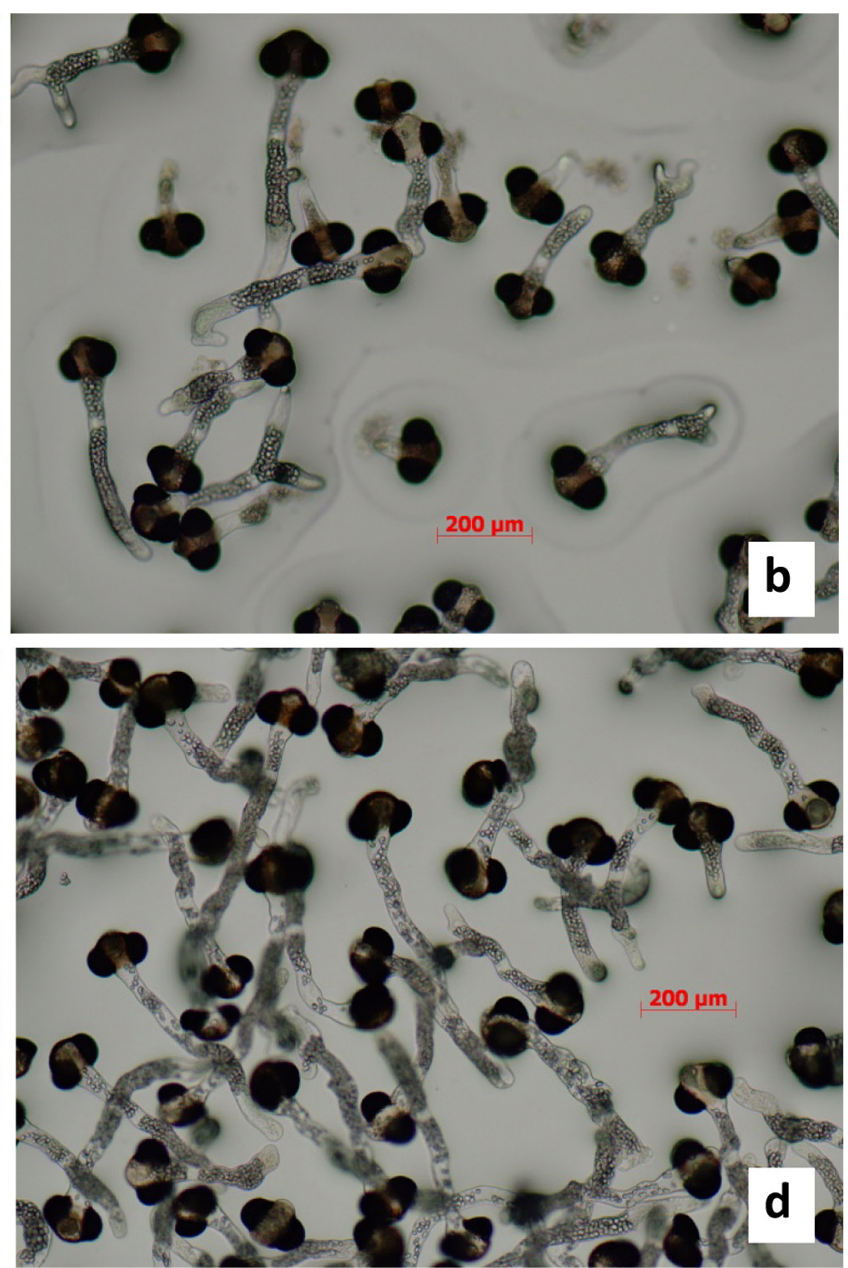
comparable characteristics of their pollen tubes and hybrid nature of the hybrid swarms which were more differentiated in their pollen tube characteristics. It was the last mentioned group of populations with both the shortest and longest pollen tubes registered in the swarms Zuberec and Obšívanka, respectively. In general, the pollen tube length of the hybrid swarms was comparable and/or higher than in freshly collected pollen of the pure species populations $P$. sylvestris and P. mugo (Table 6).

The Duncan's test confirmed a more profound differentiation between investigated populations in this viability parameter compared to germination percentage. In stored pollen grains, a variable extent of pollen viability decline was registered in individual populations. The most conspicuous was reduction of pollen germination percentage of $4.7 \%$ in hybrid swarm from Zuberec and of $4.0 \%$ in hybrid swarm from Obšívanka. In hybrid swarms from Suchá Hora this decline was of $0.6 \%$ only approaching the corresponding figure in $P$. sylvestris pollen grains with registered decline of germinability of $0.7 \%$ (Table 5). The pollen garins of $P$. mugo have surprisingly increased their germination potential of $2.4 \%$ after three years of storage in comparisom with fresh pollen. Decline of pollen germination potential in individual populations has not been paralleled by the pollen tube growth reduction. The data given in Table 6 represent the $51.4-53.4 \%$ extent of the pollen tube length decrease in all the three hybrid swarm populations and in P. sylvestris. As an exception, a relative low degree of pollen tube growth reduction in P. mugo of $21.9 \%$ only should be mentioned. In general, the data given above suggest that this pollen viability trait responds more sensitively to storage than germination percentage. Analysis of variance proved this conclusion convincingly as evidenced by the probability values for germination $(\mathrm{P}=0.0402)$ and for pollen tube length $(\mathrm{P}=0.0001)$ of the fresh and stored pollen grains. It follows from the data presented in Table 7 that in addition to storage duration, there exists also a significant inter-population variability, the populations differing significantly in their reaction to storage in both pollen viability characteristics. Naturally, individual variation was also highly significant in this respect. Among the factors studied, the interaction between fresh or stored pollen and populatiopns deviated considerably, exerting significant effect on pollen tube length only, not on pollen germination percentage.

Table 5. Germinability of fresh and 3-years stored pollen of P. sylvestris, P. mugo and their hybrid swarms

\begin{tabular}{lcccccc}
\hline \multicolumn{1}{c}{ Species/populations } & Locality & $\mathrm{N}$ & $\begin{array}{c}\text { Freshly collected pollen } \\
\text { mean } \pm \text { s.d. [\%] }\end{array}$ & $\begin{array}{c}\text { Stored pollen } \\
\text { mean } \pm \text { s.d. [\%] }\end{array}$ & $\begin{array}{c}\text { Decrease } \\
{[\%]}\end{array}$ & Duncan grouping \\
\hline P. sylvestris & Hruštin & 63 & $88.2 \pm 7.6$ & $87.6 \pm 8.5$ & 0.7 & $\mathrm{C}$ \\
P. mugo & Vrátna valley & 30 & $93.0 \pm 16.19$ & $95.2 \pm 3.2$ & 2.4 & $\mathrm{~A}$ \\
Hybrid swarm & Zuberec & 60 & $92.3 \pm 7.8$ & $88.0 \pm 16.3$ & 4.7 & $\mathrm{~B}$ \\
Hybrid swarm & Obšívanka & 21 & $95.4 \pm 5.1$ & $91.6 \pm 8.3$ & 4.0 & $\mathrm{~A}$ \\
Hybrid swarm & Suchá hora & 42 & $93.9 \pm 4.3$ & $92.7 \pm 9.6$ & 0.6 & $\mathrm{AB}$ \\
\hline
\end{tabular}

$\mathrm{N}$ - number of evaluated samples (Petri disches) corresponding to three replications of each tree of the respective population. Different letters of Duncan's test indicate significant differences between individual populations across both fresh and stored pollen.

Table 6. Pollen tube length of fresh and 3-years stored pollen of P. sylvestris, $P$. mugo and their hybrid swarms

\begin{tabular}{lcrrrrc}
\hline \multicolumn{1}{c}{ Species/populations } & Locality & $\mathrm{N}$ & $\begin{array}{c}\text { Freshly collected pollen } \\
\text { mean } \pm \text { s.d. }[\mu \mathrm{m}]\end{array}$ & $\begin{array}{c}\text { Stored pollen } \\
\text { mean } \pm \text { s.d. [ } \mu \mathrm{m}]\end{array}$ & $\begin{array}{c}\text { Decrease } \\
{[\%]}\end{array}$ & Duncan grouping \\
\hline P. sylvestris & Hruštin & 1890 & $125.13 \pm 81.28$ & $59.9 \pm 33.74$ & 52.2 & $\mathrm{D}$ \\
P. mugo & Vrátna valley & 900 & $129 \pm 42.36$ & $101.1 \pm 44.80$ & 21.9 & $\mathrm{~A}$ \\
Hybrid swarm & Zuberec & 1800 & $118.4 \pm 48.52$ & $56.0 \pm 32.79$ & 52.8 & $\mathrm{E}$ \\
Hybrid swarm & Obšívanka & 630 & $143.4 \pm 49.64$ & $69.83 \pm 34.88$ & 51.4 & $\mathrm{~B}$ \\
Hybrid swarm & Suchá hora & 1260 & $134.15 \pm 52.76$ & $61.49 \pm 32.17$ & 54.3 & $\mathrm{C}$ \\
\hline
\end{tabular}

$\mathrm{N}$ - number of measured pollen tubes corresponding to three replications of 30 pollen tubes of each tree in the respective population. Different letters of Duncan's test indicate significant differences between individual populations across both fresh and stored pollen.

Table 7. Analysis of variance of pollen germinability and polen tube length in fresh and 3-years stored pollen grains

\begin{tabular}{lrrrrrr}
\hline \multirow{2}{*}{ Source } & \multicolumn{3}{c}{ Germination percentage } & \multicolumn{3}{c}{ Pollen tube length } \\
\cline { 2 - 7 } & DF & F & P & DF & F & P \\
\hline Fresh-stored pollen & 1 & 4.24 & 0.0402 & 1 & 4531.6 & 0.0001 \\
Populations & 4 & 3.36 & 0.0144 & 4 & 3.82 & 0.0091 \\
Fresh-stored $\times$ population & 4 & 1.87 & 0.1158 & 4 & 72.11 & 0.0001 \\
Individuals (Popul.) & 67 & 6.42 & 0.0001 & 47 & 7.52 & 0.0001 \\
Error & 355 & & & 12850 & & \\
\hline
\end{tabular}




\section{Discussion}

Several aspects have emerged during study on viability of the freshly harvested and stored pollen grains in the two species of domestic pines and their hybrids. The hybrid swarms of $P$. sylvestris and $P$. mugo were found to harbor comparable or even higher germination potential and pollen tube growth intensity than freshly collected pollen grains of the parental species. This finding provides little support to our earlier studies which revealed profound differences between pollen viability of the parental species and hybrid swarm populations. The latter were shown to produce the pollen of reduced germinability and of shorter pollen tubes (Kormuták et al., 2007) or with the retarded pollen tube growth only (Kormuták et al., 2008, 2019). Evidently, the results presented in this study do not conform fully the concept which postulates the reduced fertility of the interspecific hybrids of plants including fertility of the hybrid swarm P. pumila $\times$ P. sibirica (Stebbins, 1950; Goroshkevich, 2004). A plausible explanation of this discrepancy is the annual variation in the pollen quality due to varying climatic conditions. As an example, the pollen germination in the hybrid swarm $\mathrm{Zu}$ berec may be mentioned covering the three successive years (2005-2007) during which the $61.33 \%$, $47.15 \%$ and $62.24 \%$ germinability was registered, respectively. The corresponding pollen tube means were $74.54 \mu \mathrm{m}, 80.47 \mu \mathrm{m}$ and $67.79 \mu \mathrm{m}$ (Kormuták et al., 2007, 2008). It is reasonable to assume that remarkably increased pollen viability characteristics registered in the present paper are also conditioned climatically. As far as the stored pollen is concerned, it is important to point out that contemporary interest of pollen storage biology is rather low, the main achievements in the area dating back to the 40-70ieth of the last century. In recent years, the pollen storage remains a substantial part of the forest tree breeding programmes based on controlled pollination. Studying physical and nutritional requirements in several forest tree species, Johnson (1943) was not able to reveal the differences in P. banksiana and P. sylvestris pollen germination rate after one year storage at $+2^{\circ} \mathrm{C}$. Both species were reported to retain their germination at the $90 \%$ level. Likewise, neither pollen germination percentage nor pollen tube length were reported by Ostrolucká et al. (2003) to decrease during a 1-year storage of $P$. mugo pollen at $+4^{\circ} \mathrm{C}$. Of interest is also the experiment by Chira (1971) with storage of pine pollen at room temperature. Among 20 species used so far, 14 species preserved germination potential of their pollen for 54 days, whereas 6 species lost the viability during the scored time. The pollen of $P$. sylvestris and $P$. mugo retained their longevity for 47 days only. The attempt by Surso (1989) to preserve viability of $P$. sylvestris pollen grains under laboratory conditions was accompanied by a sharp decrease of pollen germinability during the first 45 days storage followed by a complete lost of its viability in the next 75-100 days. Obviously, such a large extent of pollen germinability decline is due to the high storage temperature which is of critical importance in this respect. Our data which are based on a freeze storage at $-20^{\circ} \mathrm{C}$ for the period of 3 years are of lower magnitude. They are comparable with the results presented by Surso (1989) for P. sylvestris pollen which exhibited $61.7 \%$ germination before storage and $51.9 \%$ after 3 -years storage at $-18^{\circ} \mathrm{C}$. A total decline reached $4.3 \%$. A 3-years storage at $-18^{\circ} \mathrm{C}$ and $35-40 \%$ R.H. is considered by the author to be optimal for storage of pine pollen. For a prolong storage, the cryopreservation is recommended instead.

The data presented above highlights a serious drawback of some studies on pollen storage which have been focused preferentially on pollen germination percentage neglecting pollen tube growth. The latter is an indisputable part of the pollen viability fulfilling a key role in fertilization process. Our study revealed much higher sensitivity of pollen tube growth towards storage than pollen germination percentage. Corresponding decline of pollen tube growth in stored pollen reached more than $50 \%$. This is consistent with the findings by Duffield (1954) who reported of higher sensitivity of pollen tube growth in pines to storage and incubation conditions than germination percentage. Pukacki and Chałupka (2003) registered $8-10 \%$ decrease of pollen germination and $30 \%$ reduction of pollen tube length after 16 months storage of $P$. sylvestris pollen at $-30^{\circ} \mathrm{C}$ in trees affected by the industrial pollutants. Insufficient length of pollen tubes indicates a lowered vitality of the pollen what may be taken for a serious obstacle in penetrating nucellar tissue of an ovule and subsequent entering archegonia during prezygotic stage of fertilization (Dogra, 1967). As a result, due to egg fertilization blockage, only empty seeds develop. Fertilization capacity of three years stored pollen of $P$. sylvestris and P. contorta was found to be higher from storage at $-18^{\circ} \mathrm{C}$ in comparison with pollen stored at $+4^{\circ} \mathrm{C}$ (Ehrenberg, 1960). Also, the percentage of filled seeds in $P$. monticola was higher after pollination with fresh pollen but in total seed set per cone, a one year stored pollen of the species at $+4^{\circ} \mathrm{C}$ gave sometimes higher percentage of filled seeds (Wright, 1959). On the contrary, Stanley (1962) found that P. ponderosa pollen, after 15 year's storage at $10 \% \mathrm{R}$. $\mathrm{H}$. and $0-5^{\circ} \mathrm{C}$, gave $75 \%$ germination, but produced only hollow seeds under controlled pollinations. It is reasonable to assume a complete absence of fertilization and/or embryogeny due to retarded pollen tube growth after storage.

Still other aspects of the present study which are worth of mentioning refer to the method of pollen 
viability estimation. The $10 \%$ concentration of sucrose in cultivation medium used throughout the whole experiment was also proved by Razmologov (1964) for germination of pine pollen grains. The author recommend in vitro germination test to last 4-5 days during which the pollen tubes develop fully. We have restricted this period to the two days only to avoid using into account the pollen grains with desintegrated pollen tubes occurring often after this period of incubation

\section{Conclusions}

Although no alternative to freeze storage has been tested in the present study, the storage of pine pollen at $-20^{\circ} \mathrm{C}$ seems to offer a more reliable way of pollen viability preservation than storage at $0-4^{\circ} \mathrm{C}$. The experience accumulated in this field of research in the past indicates that storage of pollen in a refrigerator is acceptable for the period of one year only to overcome the obstacles to artificial pollination between the two seasons. Likewise, the short-term storage at room temperature may be recommended to cope with the differences in pollen shedding of the paternal trees and receptivity of the ovules in maternal trees during a given season. Functionality tests based on utilization of stored pollen in controlled pollination is the only way how to provide conclusive evidence on fertilizing ability of stored pollen. Generally, the interspecific hybrids of pines are considered to exhibit lower viability of their pollen compared to the parental species. In our study, the hybrid swarms of Scots pine and mountain dwarf pine deviated conspicuously from the parents by unexpectedly low dropping of their pollen gerimantion percentage during three years of freeze storage. This aspect remains to be answered by further experiments as well.

\section{Acknowledgement}

This study was financially supported by the VEGA Grant Agency, project no. 2/0022/20.

\section{References}

Binder WD, Mitchell GM \& Ballantyne DJ (1974) Pollen viability testing storage and related physiology. Canadian Forestry Service, Pacific Forest Research Centre, Victoria, B. C., Report BC-X-105.

Brewbaker JL \& Kwack BH (1963) The essential role of calcium ion in pollen germination and pollen tube growth. American Journal of Botany 50: 859-865.

Chira E (1971) Metódy cytogenetiky v šlachtení lesných drevín. Priroda, Bratislava.
Copes DL (1985) Fertility of Douglas-fir pollen after one year of storage in liquid nitrogen. Forest Science 31: 569-574.

Dogra PD (1967) Seed sterility and disturbances in embryogeny in conifers with particular reference to seed testing and tree breeding in Pinaceae. Studia Forestalis Suecica 45: 1-97.

Duffield JW (1954) Studies on extraction, storage and testing of pine pollen. Zeitschrift für Forstgenetik und Forstphlanzenzüchtung 3: 39-45.

Ehrenberg CE (1960) Studies on the longevity of stored pine pollen (Pinus sylvestris L. and P. contorta var. Murrayana Engelm.). Meddelanden Från Statens Skogsforskningsinstitut 49: 1-31.

Johnson LPV (1943) The storage and artificial germination of forest tree pollen. Canadian Journal of Research 21: 332-342.

Goroshkevich SN (2004) Natural hybridization between Russian stone pine (Pinus siberica) and Japanese stone pine (Pinus pumila): Breeding and genetic resources of five-needle Pines: growth, adaptability, and pest resistance (ed. by RA Sniezko, S Samman, SE Schlarbaum \& HB Kriebel) Proceedings of the IUFRO Five-Needle Pines Working Party Conference, July 23-27, 2001, Medford, Oregon, USA, pp. 169-174.

Kormuták A, Bohovičová J, Vooková B \& Gömöry D (2007) Pollen viability in hybrid swarm populations of Pinus mugo Turra and P. sylvestris L. Acta Biologica Cracoviensia, Series Botanica 49: 61-66.

Kormuták A, Vooková B, Čamek V, Boleček P \& Gömöry D (2008) Pollen size and viability in hybrid swarm populations of Pinus mugo Turra and Pinus sylvestris L. Thaiszia - Journal of Botany 18: 93-100. https://www.upjs.sk/public/media/3476/093-100-kormutak-et-al-upr.pdf.

Kormuták A, Brana M, Galgóci M, Maňka P, Sukeníková D, Libantová J \& Gömöry D (2019) Pollen fertility and seed viability of putative hybrid swarms of Pinus sylvestris and Pinus mugo in Slovakia. Silvae Genetica 68: 14-21. doi:10.2478/sg-2019-0003.

Mercier S (1995) The role of pollen bank in the forest genetic improvement program in Québec (Canada). Grana 34: 367-370.

Nepamuceno Martínez F \& Garza López P (1994) Efecto del contenido de humedad sobre la viabilidad del polen de tres especies de coníferas. Ciencia Forestal en México 19: 63-76.

Ostrolucká MG, Čičová L \& Bolvanský M (2003) Influence of temperature and storage on pollen viability in Pinus mugo Turra. Folia Oecologica 30: 157-162.

Pukacki PM \& Chałupka W (2003) Environmental pollution changes in membrane lipids, antioxidants and vitality of Scots pine (Pinus sylvestris L.) pollen. Acta Societatis Botanicorum Poloniae 72: 99-104. 
Razmologov VP (1964) O vyrashhivanii i khranenii pyl'cy nekotorykh golosemennykh rastenij. Bjulletin Glavnogo Botanitscheskogo Sada, Moscow 52: 79-87.

Snyder EB (1961) Extracting, processing, and storing southern pine pollen. Southern Forest Experimental Station, U. S. Forrest Service, Occasional Paper 191.

Stanley RG (1962) Viable píne (Pinus ponderosa) pollen stored 15 years produced unsound seed. Silvae Genetica 11: 164.
Stanley RG \& Linskens HF (1974) Pollen. Biology, biochemistry, management. Springer-Verlag, Berlin-Heidelberg-New York.

Stebbins GL Jr (1950) Variation and evolution in plants. Columbia University Press, New York.

Surso MV (1989) Vlijanie dlitel'nogo chranenija pyl'cy na formirovanie semjan sosny obyknovennoj. Nauchnije doklady of the USSR, Ural Division, Komi Scientific Center, Issue 214: 19.

Wright JW (1959) Species hybridization in the white pines. Forest Sciences 5: 210-222. 